\title{
ESPAÇO LITERÁRIO, PERCEPÇÃO E PERSPECTIVA
}

\author{
Paulo Astor Soethe \\ UFPR
}

\begin{abstract}
RESU MO
$\mathrm{O}$ artigo fundamenta a abordagem do espaço literário como elemento composicional particularmente atento à percepção do entorno pelas personagens. Define espaço literário e revisita, sob esse aspecto, o motivo da travessia no romance Grande sertão: veredas.
\end{abstract}

\section{PALAVRAS - CHAVE}

Espaço literário. Percepção. Literatura e ética. Guimarães Rosa.

O presente artigo tece considerações teóricas e aponta para resultados obtidos sob a linha de pesquisa "Literatura e experiência de espaço" no âmbito do Programa de Pós-graduação em Letras da Universidade Federal do Paraná.

Apresentei e desenvolvi em trabalho anterior alguns fundamentos da abordagem da conformação do espaço no texto narrativo ficcional voltada à investigação da força declarativa ética desse elemento composicional. ${ }^{1}$

As análises e reflexões de que se trata aqui partem da seguinte noção: a elaboração literária de narrativas ficcionais mostra-se particularmente atenta ao fato social e cognitivo de que perceber o espaço possibilita conceber a imersão dos sujeitos perceptivos em um mundo partilhado. Pois figurar o espaço é tematizar condicionamentos recíprocos entre figuras humanas e seu entorno, mas também problematizar as relações entre as figuras humanas, elas mesmas, na partilha de espaços comuns. Dar forma literária ao

\footnotetext{
${ }^{1}$ Cf. SOETHE. Thomas Mann e Guimarães Rosa. Sobre literatura e ética, de maneira geral, há vasta bibliografia, que me eximo de listar aqui, exceto duas obras mais recentes, a saber: ROCHE. Die Moral der Kunst e MANDRY. Literaturwissenschaft und Ethik im Gespräch. Preparo relatório de pesquisa sobre a questão, para publicar em breve. Da mesma forma, está em fase de conclusão um estudo sobre a teoria e análise do espaço literário na tradição de língua alemã. A pesquisa para a realização dos dois trabalhos deu-se durante programa de pós-doutorado na Universidade de Tübingen, proporcionado pela Fundação Alexander von Humboldt. Pouco antes do início dessa pesquisa, foi uma grande satisfação conhecer o trabalho e a pessoa de Luis Alberto Brandão (BRANDÃO. Breve história do espaço na teoria da literatura, entre outros), primus inter pares na área de estudos sobre o espaço literário no Brasil. Seu Tablados é um momento de grande êxito na confluência entre produção literária e reflexão poética, em particular sobre o espaço em literatura.
} 
espaço equivale a conformar verbalmente a linha de separação e união entre a personagem como sujeito perceptivo e o que está fora dela; equivale a distinguir e situar as coisas delimitáveis no mundo que as personagens habitam e a explicitar processos de percepção do entorno pelas personagens. Equivale também, não raro, a destacar nas personagens a noção do ilimitado, dada a dimensão potencialmente infinita do espaço enquanto meio físico e forma da intuição. E equivale a figurar, no horizonte das personagens, a percepção de outros indivíduos por elas e o deslocamento de sua perspectiva subjetiva para outros pontos, quando podem ver a partir da perspectiva de outros, de modo objetivo.

Esses elementos são fundamentais tanto para a dicção literária quanto para a dicção reflexiva nas humanidades. Não raro recorre-se na filosofia, por exemplo, a imagens e descrições espaciais para propor fundamentos da ética. Veja-se, por exemplo, o deslocamento da perspectiva subjetiva para outros pontos de vista na observação da paisagem, como índice da experiência de descentração. A movência do foco de observação subjetivo para outros centros imaginários, de onde o indivíduo pode ver-se objetivamente, sinaliza amadurecimento ético e existencial. Espacial por excelência, e vinculada à percepção em um primeiro momento, a experiência de descentração é constitutiva do pensamento ético. Veja-se o que escreve, por exemplo, a partir do conceito de posição excêntrica de Helmuth Plessner (1892-1985), o filósofo alemão contemporâneo Robert Spaemann:

Considerar a própria vida sob o ponto de vista de seu sucesso no todo é a peculiaridade de um ser cujo espaço de realidade é infinito, ou seja, de um ser que se distingue do animal por não estar mais centrado em torno de si mesmo. Quem navega sobre o oceano, dia após dia, está no centro do círculo de um enorme território marítimo que é capaz de vislumbrar. Porém, sobre o mapa de navegação é fixada a cada dia uma pequena bandeira que demarca a posição do navio com base em parâmetros neutros face a essa posição peculiar. Sensorialmente, sentimo-nos no centro do mundo. Mas aquela vivência, que se chama saber, faz-nos entender que nos encontramos à margem do horizonte, se somos vistos de perspectivas diferentes, situadas em outros centros. Para o animal, o mundo é apenas o mundo que o rodeia. Nós, porém, sabemos - ou seja, isso é uma realidade para nós - que nós mesmos também integramos o mundo que rodeia outros seres e que é percebido por eles. Essa "posição excêntrica" (Helmuth Plessner) possibilita que o ser humano seja capaz de imaginar a própria vida como um todo. ${ }^{2}$

Ora, nos textos ficcionais o espaço pressupõe a utilização de recursos verbais que explicitem a percepção do entorno pelas personagens. E quando se trata de refletir sobre a percepção e sobre o sentido da percepção do espaço, as obras literárias são fonte privilegiada: por seu caráter imaginário e mimético, elas se mostram capazes de evocar a "contribuição perpétua" da corporeidade do sujeito 3 sob formas plásticas e sensoriais, mais do que com argumentos e abstrações. Os textos literários fazem jus à percepção do espaço enquanto "comunicação com o mundo mais velha que o pensamento". ${ }^{4}$

O papel central da visão dos objetos para o sujeito perceptivo em meio ao espaço é contemplado nas obras literárias com a descrição do entorno, figuras humanas e objetos com os quais se defrontam as personagens. Pois o que fundamenta a conformação ficcional

\footnotetext{
${ }^{2}$ SPAEMANN. Felicidade e benevolência, p. 103.

${ }^{3}$ Cf. MERLEAU-PONTY. Fenomenologia da percepção, p. 342.

${ }^{4}$ MERLEAU-PONTY. Fenomenologia da percepção, p. 342.
} 
da percepção do espaço por elas é a descrição da forma visual como limite que delineia e separa corpos e objetos do meio e entre si, ou seja, a reordenação imaginária, pela linguagem, do traçado, textura, volumes e cores das coisas e paisagens percebidas.

A percepção e apreensão consciente da superfície tênue a envolver os objetos, e o corpo em especial, funda a forma, definida de modo tão sugestivo por Max Frisch ${ }^{5}$ como "uma espécie de limite sonante", uma "superfície imaterial, que existe apenas para o espírito e não na natureza, na qual também inexiste o traço entre a montanha e o céu”.

Essa visão fenomenológica do entorno em narrativas ficcionais revela-se um ponto de partida fértil para a abordagem e análise do espaço em literatura enquanto verbalização da experiência de percepção (sobretudo visual) do próprio corpo, do entorno e do outro humano pelo sujeito perceptivo. Essa escolha metodológica pretende superar a imprecisão conceitual recorrente em abordagens do espaço em literatura, que exemplifico com a seguinte citação de Bodo Assert, na introdução de seu trabalho sobre o tema:

O espaço em si nunca é posto em questão na literatura (exceto no caso, perfeitamente concebível, de que um herói ou um narrador reflitam sobre esse espaço, o que ele sempre tem que fazer, no entanto, imerso em um espaço determinado). O espaço em sua extensão tridimensional, em sua abstração e generalidade não será levado em consideração aqui [no trabalho que ele escreve]. [...] Em literatura, o espaço seria constituído pelos objetos (pessoas, animais e coisas), bem como suas relações entre si [...]. O espaço em literatura teria em primeiro lugar um sentido de conteúdo. ${ }^{6}$

Se por um lado Assert pretende excluir a abordagem de um espaço em abstrato pela literatura, demonstrando uma propensão fenomenológica para sua abordagem, ele se contradiz ao afirmar que o "espaço em si" nunca é posto em questão na literatura, mas só através de objetos e suas relações. E não raro os autores trazem, sim, à tona o conceito de espaço nas reflexões de suas personagens. ${ }^{7}$ Para evitar esse tipo de dissociação entre um conceito intelectualista de espaço e outro, empirista, sendo que pouco se atenta para sua realidade sobretudo verbal, é que opto por sua definição em literatura como fruto da percepção de um sujeito ficcional diante de seu entorno e dos objetos, como resultado desse "poder do sujeito sobre o mundo". Só há, em literatura, espaço sobre o qual se possa falar, espaço que seja percebido por um sujeito em sua presença no mundo.

Assumo, diante disso, a definição do espaço literário como conjunto de referências discursivas, em determinado texto ficcional e estético, a locais, movimentos, objetos, corpos e superfícies, percebidos pelas personagens ou pelo narrador (de maneira efetiva ou imaginária) em seus elementos constitutivos (composição, grandeza, extensão, massa, textura, cor, contorno, peso, consistência), e às múltiplas relações que essas referências estabelecem entre si. Esse conjunto constitui o entorno da ação e das vivências das personagens no texto e surge sob a visão mediadora de um ou mais sujeitos perceptivos no interior da obra, que o apreendem (ou imaginam) e que elaboram verbalmente o resultado

\footnotetext{
${ }^{5}$ Anotação em diário (Tagebuch 1946-1949), Gesammelte Werke II/2 (1944-1949). Frankfurt/M.: Suhrkamp, 1976. p. 378-379 (apud KUSCHEL. Im Spiegel der Dichter, p. 285).

${ }^{6}$ ASSERT. Der Raum in der Erzählkunst, p. 8. Tradução minha.

${ }^{7}$ Veja-se, a seguir, a breve análise de aspectos da obra de João Guimarães Rosa. E, recentemente, KOEHLER. Lugar sertão se divulga.
} 
da percepção (própria ou alheia, seja com recursos objetivos e descritivos, seja com formulações criativas, metafóricas e associativas).

A diversidade de recursos de elaboração verbal da percepção do espaço e as muitas formas de relação subjetiva e social com ele são fator decisivo para a constituição de sentido no texto literário, e em especial, de sentido ético.

\section{II}

Para ilustrar tal argumento, tome-se o motivo da travessia em Grande sertão: veredas, inicialmente a partir de um episódio da travessia de uma superfície aquática, motivo caro ao imaginário ocidental já em suas fontes remotas (por exemplo, Jesus na barca com seus discípulos, a acalmar os ventos e as ondas, e Caronte, na mitologia grega ou em Dante). Tem-se aí um bom caso da utilização de noções espaciais para a conformação do pensamento no romance de Guimarães Rosa. Riobaldo conhece o menino ReinaldoDiadorim durante a travessia de um rio, ${ }^{8}$ e diversas outras travessias fluviais integram seu itinerário pelo sertão, como jagunço. São exemplos a travessia do rio São Francisco e chegada ao Urucuia ${ }^{9}$ e a travessia do Paracatu e riachos próximos. ${ }^{10}$ Mesmo a passagem do desértico Liso do Sussuarão é caracterizada como "travessia do raso", ${ }^{11}$ e associada a imagens aquáticas:" "Soltando rédeas, entrei nos horizontes. Aonde entrei, na areia cinzenta, todos me acompanhando. E os cavalos, vagarosos; viajavam como dentro de um mar". ${ }^{13}$ A noção de travessia, além disso, autonomiza-se e presta-se a ilustrar divagações de caráter mais geral, constituindo um dos principais temas do romance:

Ah, tem uma repetição, que sempre outras vezes em minha vida acontece. Eu atravesso as coisas - e no meio da travessia não vejo! - só estava era entretido na idéia dos lugares de saída e de chegada. Assaz o senhor sabe: a gente quer passar um rio a nado, e passa; mas vai dar na outra banda e num ponto muito mais embaixo, bem diverso do em que primeiro se pensou. Viver nem não é muito perigoso? ${ }^{14}$

Outra vez, logo adiante: "Digo: o real não está na saída nem na chegada: ele se dispõe para a gente é no meio da travessia". ${ }^{15}$ E nem se precisaria mencionar que "travessia" encerra o romance, mediando o caminho entre a condição do "homem humano" e o infinito grafado para além da linguagem natural “ $\infty$ ", como símbolo.

Mais do que sugerir uma suspensão de sentidos que remeteria o leitor a uma realidade inapreensível, por conta de sua dinamicidade, o termo aponta justamente

\footnotetext{
${ }^{8}$ ROSA. Ficção completa, p. 70-74.

${ }^{9}$ ROSA. Ficção completa, p. 196-197.

${ }^{10}$ ROSA. Ficção completa, p. 295.

${ }^{11}$ ROSA. Ficção completa, p. 321.

${ }^{13}$ ROSA. Ficção completa, p. 322.

${ }^{14}$ ROSA. Ficção completa, p. 28.

${ }^{15}$ ROSA. Fiç̧ão completa, p. 46.
}

${ }^{12}$ Fala-se também em "navegar o sertão" (ROSA. Ficção completa, p. 202). Sobre as imagens aquáticas e náuticas em Grande sertão: veredas, ver respectivamente COSTA. (A) Claráguas ou a simbologia do elemento aquático em Grande sertão: veredas; GALVÃO. Metáforas náuticas. 
para o que se pode apreender, quando se trata da realidade do sujeito em sua ambivalência. Se Riobaldo, nas citações acima, afirma não pode ver o que ocorre enquanto "atravessa as coisas", ele mesmo justifica isso por estar "entretido na idéia de lugares de saída e de chegada". Além disso, é clara a afirmação de que "o real [...] se dispõe para a gente é no meio da travessia" (grifos meus). Toda a narração de Riobaldo, afinal, é tentativa de redispor através da linguagem esse meio-do-caminho ao qual ele diz não haver estado suficientemente atento no calor dos acontecimentos.

Há uma analogia entre a noção espacial de extensão entre dois pontos (dimensão do espaço), e de deslocamento de um corpo entre esses mesmos pontos (orientação no espaço). A percepção e apreensão dessa realidade torna-se possível ao leitor e ao personagem por uma unidade de sentido figurativa, que fixa a dimensão em imagens visuais dinâmicas, como a de um rio, ou de um mar, no caso do Liso do Sussuarão; a orientação, por sua vez, deve-se à descrição progressiva da percepção dessas imagens visuais, pelo narrador, e da interação com outros sujeitos que aí se encontram.

A imersão do sujeito no tempo (pela narração) e em seu mundo circundante (pelas descrições visuais e referências à percepção) confere substância à travessia, que se oferece plasticamente ao personagem e ao leitor, na linguagem. A condição ambivalente do sujeito (espírito e natureza), presente na conformação figurativa dos espaços de "travessia", em suas várias formas, considera a existência física e natural do personagem. Atribui ao indivíduo visualidade e materialidade corpórea na linguagem, mas também possibilita a inscrição de seus atos e palavras no universo simbólico, cultural e ético das relações que aí se estabelecem. A travessia corresponde à mediação entre as pulsões do "homem humano" e os anseios totalizantes e etéreos do espírito, aberto para o infinito e ansioso pelo "definitivo da questão", como diz Riobaldo, ${ }^{16}$ mas sediado, de fato, na vida natural e histórica dos personagens.

A expressão "homem humano" estar ligada sobretudo à existência impulsiva e passional dos sujeitos é uma indicação do próprio romance. Na última ocorrência da expressão antes de sua menção na conclusão do texto, ${ }^{17}$ o bando dos jagunços está sob o comando já pálido de Zé Bebelo, na região do Sucruiú. O momento é marcado pela doença e pelo desânimo, mas também pela solidariedade no grupo, em função dos cuidados exigidos pela enfermidade. Riobaldo oscila entre a identificação com os companheiros e a rejeição do código comportamental e ético do grupo. Um dos sertanejos, Sidurino, para quebrar a situação de desalento do grupo, sugere empreender um "tiroteio a alguma vila sertaneja dessas, e se pandegar, depois, vadiando...”. ${ }^{18}$ De início, Riobaldo aprova a sugestão, mas logo reavalia seu juízo:

Aprovei, também. Mas, mal acabei de pronunciar, eu despertei em mim um estar de susto, entendi uma dúvida [...]. Aqueles ali, eram com efeito os amigos bondosos, se ajudando uns aos outros com sinceridade [...]. Mas, no fato, por alguma ordem política, de se dar

\footnotetext{
${ }^{16}$ ROSA. Ficção completa, p. 16.

${ }^{17}$ Há outra ocorrência de "homem humano" na p. 40 do romance, também em um contexto extremo, em que o bando, após desistir da travessia do Liso do Sussuarão, mata e devora um "homem humano", pensando tratar-se de um macaco.

${ }^{18}$ ROSA. Ficção completa, p. 259.
} 
fogo contra o desamparo de algum arraial, de outra gente, gente como nós, com madrinhas e mães - eles achavam questão natural, que podiam salientemente cumprir, por obediência saudável e regra de se espreguiçar bem. O horror que me deu - o senhor me entende? Eu tinha medo de homem humano. ${ }^{19}$

Riobaldo assusta-se consigo mesmo por descobrir-se duplo. Embora conserve parâmetros de outro universo ético e cultural, o personagem vê-se imerso na lógica de um bando que, naquele momento, se agrega em torno do prevalecimento da barbárie (violência e abuso contra inocentes: "tiroteio", "pândega" e "vadiagem" contra um arraial de civis, com "madrinhas e mães"). A expressão "homem humano", apesar de imbuída dessa ambivalência, surge em um contexto de ênfase a esse lado ameaçador do homem.

A noção da travessia como figuração espacial da existência ambivalente do ser humano ao longo da vida e diante do entorno material ganha nova dimensão quando associada ao sertão.

O bando de Riobaldo busca o encontro com os inimigos, para a batalha final. Por uma região serrana, de chapadas, os homens voltam a entrar em território mineiro, depois de ter estado em terras goianas, para fazer refém a mulher de Hermógenes. A situação é descrita da seguinte maneira:

E piorou um tico o tempo, em Minas entramos, serra-acima, com os cavalos esticados. [...] no remedido do trivial, espaço de chuva, a gente em avanço por esses tabuleiros: fazia rio, por debaixo, entre as pernas de meu cavalo. Sertão velho de idades. Porque - serra pede serra - e dessas, altas, é que o senhor vê bem: como é que o sertão vem e volta. Não adianta se dar as costas. Ele beira aqui, e vai beirar outros lugares, tão distantes. Rumor dele se escuta. Sertão sendo do sol e os pássaros: urubu, gavião - que sempre voam às imensidões, por sobre... Travessia perigosa, mas é a da vida. Sertão que se alteia e se abaixa. ${ }^{20}$

O comentário superpõe várias situações de transição. Em primeiro lugar, cruza-se a fronteira entre Goiás e Minas, mencionada diversas vezes no romance. É para Goiás que Zé Bebelo é banido, depois de seu julgamento; e de lá é que volta para organizar a vingança pela morte de Joca Ramiro. É em Goiás que Hermógenes tem suas terras e familiares. E também as diferenças lingüísticas acentuam a fronteira entre os dois estados: "E o caminho nosso", Riobaldo comenta pouco antes do retorno a Minas, "era retornar para essas gerais de Goiás - como lá alguns falam. O retornar para estes gerais de Minas Gerais". ${ }^{21}$ A variação do gênero da palavra é elemento a mais na constituição das fronteiras, algo mais que meramente convencionais e imaginárias.

Em segundo lugar, o tempo piora, e a chuva forma um "rio, por debaixo, entre as pernas" do cavalo de Riobaldo. Como ocorrera antes, em um riacho próximo ao rio Paracatu, o cavalo entra em destaque como meio de passar o rio. Naquela travessia anterior, um detalhe chamava a atenção para o animal, que se confundia com o montador: "Todo mundo passou, por tanto, diante de mim, eu esbarrado em pé - isto é, a cavalo". 22 E logo depois, na mesma página, ao se cruzar o Paracatu: "Esbarrei não, nem examinei o

\footnotetext{
${ }^{19}$ ROSA. Ficção completa, p. 259.

${ }^{20}$ ROSA. Ficção completa, p. 344.

${ }^{21}$ ROSA. Ficção completa, p. 337.

${ }^{22}$ ROSA. Ficção completa, p. 295.
} 
adiante. Demiti meu cavalo n'água. Os outros me acompanharam. Assim atravessamos". Há na travessia de Minas para Goiás uma dupla referência a travessias anteriores: a imagem de um "rio" formado pela chuva é enfatizada também pela atenção ao cavalo como meio utilizado para atravessá-lo.

Em terceiro lugar, a travessia é perpassada pela visão de conjunto do próprio sertão, que envolve o protagonista por todos os lados e delimita para ele seu mundo, tal como percebido por Riobaldo a partir da própria corporeidade. À beira do rio Paracatu, em episódio anterior, uns versos de Riobaldo já haviam chamado a atenção para esse aspecto. A imagem do sertão como "sombra" do chefe Riobaldo, sua ação e presença no mundo, pelo corpo e pelas armas, sugeria sentido semelhante:

\section{Travessia dos Gerais tudo com armas na mão... O Sertão é a sombra minha e o rei dele é Capitão! ...23}

Em breve, porém, o sertão autonomiza-se como realidade para além do domínio de Riobaldo, ao menos no que diz respeito à apreensão de sua totalidade. A afirmação de que o sertão é "do sol e os pássaros: urubu, gavião" que "voam, por sobre..." 24 ficará mais clara apenas vinte páginas adiante: "Sei o grande sertão? Sertão: quem sabe dele é urubu, gavião, gaivota, esses pássaros: eles estão sempre no alto, apalpando ares com pendurado pé, com o olhar remidindo a alegria e as misérias todas...". ${ }^{25}$ A perspectiva dos pássaros, ${ }^{26}$ nos dois casos, permite a visão abrangente do sertão. Ele se apresenta então como metáfora para a vida das pessoas, sua "alegria e as misérias todas". Pois na volta de Goiás para Minas, logo após a referência a essa visão de cima, explicita-se a comparação: "Travessia perigosa, mas é a da vida. Sertão que se alteia e se abaixa".

O exercício imaginário de deslocamento do ponto de vista do sujeito para o alto, esse vôo do espírito que descentraliza o sujeito de sua própria corporeidade (embora ela sempre permaneça como pouso necessário para depois da divagação), amplia em Grande sertão: veredas o horizonte da reflexão ética e filosófica. A tripla travessia a que me referi - da fronteira entre Minas e Goiás, do "rio" formado pela chuva, e do sertão como espaço geográfico e metáfora da vida do sujeito - pressupõe ainda o livre trânsito do leitor pelo texto, através de antecipações e retrospecções necessárias para a construção de sentido na citação que fizemos. Para entender o trecho que lê, o leitor precisa altearse sobre o romance e vê-lo no todo, auxiliado pela força sintetizadora da memória, a partir dos indícios proporcionados pela conformação pictórico-figural do espaço de travessia e das metáforas associadas a ele. ${ }^{27}$

\footnotetext{
${ }^{23}$ ROSA. Ficção completa, p. 295.

${ }^{24}$ ROSA. Ficção completa, p. 344.

${ }^{25}$ ROSA. Ficção completa, p. 364.

${ }^{26}$ Sobre o recurso da visão da perspectiva do pássaro ("Vogelschauperspektive"), caro à literatura satírica dos séculos XVII e XVIII, ver comentário e indicação de bibliografia em SOETHE. Sobre a sátira, p. 11-14.

${ }^{27}$ Para Bruno Hillebrand, "o espaço é $o$ elemento constituivo da memória, e portanto determinante para o processo de re-aquisição, de recondução ao pensamento. [...] Assim que se cumpre o percurso de leitura, o leitor - e tanto mais quanto maior a distância - lembra-se do trecho que atravessou e dos cenários como algo de caráter espacial". HILLEBRAND. Mensch und Raum im Roman, p. 6.
} 
Essas ascensões, por assim dizer, ou seja, o olhar do leitor que se alteia sobre o livro e a perspectiva imaginária do pássaro sobre o sertão, constituem uma das chaves para o raciocínio ético no romance. O narrador Riobaldo, no parágrafo subseqüente ao trecho com as múltiplas travessias, esclarece de forma tortuosa:

Com trovôo. Trovoadão nos Gerais, a ror, a rodo... Dali de lá, eu podia voltar, não podia? Ou será que não podia, não? Bambas asas, me não sei. Bambas asas... Sei ou o senhor sabe? Lei é asada é para as estrelas. Quem sabe, tudo o que já está escrito tem constante reforma mas que a gente não sabe em que rumo está - em bem ou mal, todo-o-tempo reformando? ${ }^{28}$

De início, as dimensões do sertão ecoam no trovão, pois há pouco, para descrever sua grandeza, afirmara-se que "rumor [do sertão] se escuta". Para o leitor atento e cumpridor de um segundo percurso pelo romance, o trovão associa-se ainda à batalha final no Tamanduá-tão, em que morre Diadorim, e isso explica a pergunta amarga de Riobaldo quanto a poder ter recuado daquele ponto para trás.

O questionamento entrança-se com as muitas menções da possibilidade de "volta do meio pra trás", presentes na canção do bando e em diversos outros momentos do romance. ${ }^{29} \mathrm{O}$ narrador Riobaldo, ciente da impossibilidade de ter assumido a "perspectiva do pássaro" sobre a vida e o sertão durante suas andanças, atribui "bambas asas" a si próprio, mesmo na condição de narrador já distanciado dos fatos.

Por fim, menções à lei, que é "asada é para as estrelas", e à "constante reforma em bem e mal" explicitam o sentido amplo da reflexão ética. A "lei", a prescrição geral e apriorística de ações e comportamentos, afasta-se da perspectiva do sujeito humano imerso em seu tempo e entorno, e pouco capaz de atingir visões de totalidade ou de saber "em que rumo está".

$\mathrm{Na}$ plasticidade das referências à percepção do espaço, os desafios da dinâmica do éthos revelam-se a Riobaldo, cujas decisões e indecisões éticas marcarão a própria vida e as lembranças da vida de jagunço.

\section{4}

\section{RESUMEN}

El artículo fundamenta el abordaje del espacio literario como elemento composicional particularmente atento a la percepción del entorno por los personajes. Define espacio literario y analisa una vez más, bajo ése aspecto, el motivo de la travesía en la novela Grande sertão: veredas.

\section{PALABRAS-CLAVE}

Espacio literario. Percepción. Literatura y ética. Guimarães Rosa.

${ }^{28}$ ROSA. Ficção completa, p. 344.

${ }^{29}$ Ver exemplo em ROSA. Ficção completa, p. 132, 186. 


\section{REFERÊNCIAS}

ASSERT, Bodo. Der Raum in der Erzählkunst. Wandlungen der Raumdarstellung in der Dichtung des 20. Jahrhunderts. 1973. 300 f. Tese (Doutoramento) - Universidade Tübingen.

BRANDÃO, Luis Alberto. Breve história do espaço na teoria da literatura. Cerrados, Brasília, n. 19, p.115-134, 2005.

BRANDÃO, Luis Alberto. Tablados. Rio de Janeiro: 7Letras, 2004.

COSTA, Marta Morais da. (A) Claráguas ou a simbologia do elemento aquático em Grande sertão: veredas. Estudos Brasileiros, v. 3, n. 4, p. 231-258, 1977.

GALVÃO, Walnice Nogueira. Metáforas náuticas. Revista do Instituto de Estudos Brasileiros, São Paulo, v. 41, p. 123-130, 1996.

HILlEBRAND, Bruno. Mensch und Raum im Roman. Studien zu Keller, Stifter, Fontane. Mit einem einführenden Essay zur europäischen Literatur. München, 1971.

KOEHLER, Jaqueline. Lugar sertão se divulga: é onde a cidade carece de fechos. (Mestrado em Letras) - Universidade Federal do Paraná, Curitiba, 2007.

KUSCHEL, Karl-Josef. Im Spiegel der Dichter. Mensch, Gott und Jesus in der Literatur des 20. Jahrhunderts. Düsseldorf: Patmos, 1997.

MANDRY, Literatur ohne Moral. Literaturwissenschaft und Ethik im Gespräch. Münster: LIT, 2003.

MERLEAU-PONTY, Maurice. Fenomenologia da percepção. Trad. Carlos Moura. São Paulo: Martins Fontes, 1996.

ROCHE, Mark William. Die Moral der Kunst. Über Literatur und Ethik. Beck, 2002.

ROSA, João Guimarães. Ficção completa. Rio de Janeiro: Nova Aguilar, 1994. v. 2.

SOETHE, Paulo Astor. Sobre a sátira: contribuições da teoria literária alemã na década de 60. Fragmentos, Florianópolis, v. 7, n. 2, p. 7-27, jan.-jun. 1998.

SOETHE, Paulo Astor. Thomas Mann e Guimarães Rosa: montanha e sertão do tamanho do mundo. In: KESTLER et al. Estudos anglo-germânicos em perspectiva. Rio de Janeiro: Faculdade de Letras da UFRJ, 2002. p. 29-41.

SPAEMANN, Robert. Felicidade e benevolência: ensaio sobre ética. Trad. Paulo Astor Soethe. São Paulo: Loyola, 1996. 